\title{
Isolation of Multiple Normal and Functionally Defective Forms of Uridine Diphosphate-Glucuronosyltransferase from Inbred Gunn Rats
}

\author{
Namita Roy Chowdhury, Frederic Gross, Albert D. Moscioni, Michael Kram, Irwin M. Arias, and Jayanta Roy Chowdhury \\ Liver Research Center, Albert Einstein College of Medicine, Bronx, New York 10461
}

\begin{abstract}
Gunn rats are a mutant strain of Wistar rats that have unconjugated hyperbilirubinemia due to absence of hepatic uridine diphosphate-glucuronosyltransferase (UDPGT; EC. 2.4.1.17) activity toward bilirubin. We isolated five UDPGT isoforms from solubilized microsomal fractions from liver of inbred Wistar (RHA) rats and congeneic Gunn rats. UDPGT isoform $V$ (elution pH 7.5) from Wistar (RHA) rats is active toward bilirubin and 4'-hydroxydimethylaminoazobenzene. The corresponding isoform from Gunn rat liver was enzymically inactive but exhibited normal elution $\mathrm{pH}$ and mobility on $\mathrm{NaDodSO}_{4} /$ polyacrylamide gel electrophoresis $\left(M_{\mathrm{r}} 53,000\right)$, and was recognized by a UDPGT-specific antiserum. UDPGT isoform I (elution pH 8.7) from Wistar (RHA) and Gunn rats was active toward 4-nitrophenol. The isoform from Gunn rat liver had only $10 \%$ of normal UDPGT activity, however UDPGT activity increased to normal upon addition of $15 \mathrm{mM}$ diethylnitrosamine in vitro. Isoforms II (elution pH 8.4), III (elution pH 8.0), and IV (elution pH 7.8) from Gunn rats had normal UDPGT activities, except that Isoform IV was inactive toward bilirubin.
\end{abstract}

\section{Introduction}

Glucuronidation is a major pathway for detoxication of relatively nonpolar metabolites, drugs, toxins, and other xenobiotics (1). Formation of glucuronides is catalyzed by uridine diphosphateglucuronosyltransferase (UDPGT), ${ }^{1}$ concentrated in hepatic endoplasmic reticulum and nuclear envelope (2), and catalyzes the transfer of glucuronic acid from UDP-glucuronic acid to a wide variety of aglycones, forming $\mathrm{O}-, \mathrm{N}-, \mathrm{S}$-, and C-glucuronides (3). Functional heterogeneity of UDPGT is suggested by different times of appearance of transferase activity toward various substrates during perinatal life in rats (4) and differential effects of enzyme-inducing agents on substrate-specific transferase activities (5-7). The concept of multiplicity of UDPGT was supported recently by chromatographic separation and isolation of multiple

Address communications to Namita Roy Chowdhury, M.D., Liver Research Center, Albert Einstein College of Medicine, Bronx, NY 10461.

Dr. Arias' current address is Department of Physiology, Tufts University Medical School, Boston, MA 02111.

Dr. Moscioni's current address is Department of Surgery, Vanderbilt University School of Medicine, Nashville, TN 37232.

Received for publication 23 June 1986.

1. Abbreviations used in this paper: DEN, diethylnitrosamine; UDPGT, uridine diphosphate-glucuronosyltransferase.

J. Clin. Invest.

(C) The American Society for Clinical Investigation, Inc. 0021-9738/87/02/0327/08 $\$ 1.00$

Volume 79, February 1987, 327-334 forms of rat liver UDPGT with distinct substrate specificities (6-13).

UDPGT-mediated glucuronidation is essential for efficient biliary excretion of bilirubin (14-16). Patients with CriglerNajjar syndrome, type I, lack hepatic UDPGT activity, exhibit life-long nonhemolytic unconjugated hyperbilirubinemia, and die of kernicterus in infancy or early adulthood. Mutant Gunn rats (17) lack hepatic UDPGT activity for bilirubin (18) and are a model for Crigler-Najjar syndrome, type I (15-20). Patients with Crigler-Najjar syndrome, type I and homozygous Gunn rats excrete only small amounts of unconjugated bilirubin in bile (19). UDPGT activity toward bilirubin is undetectable in Gunn rats (18), but activity toward simple phenolic substrates, such as 4-nitrophenol, has been reported to be normal or decreased (21-24), possibly reflecting strain differences within Gunn rats (3). In contrast, glucuronidation of aniline (25) and several steroid substrates was normal in Gunn rats $(26,27)$. UDPGT activity toward 4-nitrophenol is stimulated to normal in vitro by diethylnitrosamine, but UDPGT activity toward bilirubin is unaffected (28). Recently, a defective form of UDPGT was isolated from Gunn rat liver (29). The preparation was enzymically inactive, but activity toward 4-nitrophenol was restored on addition of diethylnitrosamine (29).

The mechanism of defective function of UDPGT in Gunn rats is not known. Because of the differences in the extent of the defect of rates of glucuronidation of various aglycones in Gunn rats and normalization of the transferase activity toward phenolic substrates in the presence of diethylnitrosamine, the presence of normal amounts of defective forms of UDPGT in the Gunn rat liver has been suggested $(24,30)$. Other authors have suggested on the basis of immunological studies that certain forms of UDPGT are absent in the liver of Gunn rats (31).

Quantitative comparison of UDPGT activity with different substrates in Gunn and Wistar rats has been difficult due to heterogeneity in both strains $(21-24,32)$. We obviated this variability by using inbred Wistar rats (RHA strain) and congeneic Gunn rats, which differ from inbred Wistar rats only in having the jaundice locus (33). We separated and purified five forms of enzymically active UDPGT from microsomal fractions of Wistar (RHA) rat livers. Five corresponding isoforms were also purified from Gunn rat liver. Although each isoform from Gunn rats was recognized by a UDPGT-specific antiserum, two isoforms that are normally active toward bilirubin and 4-nitrophenol were functionally defective. The remaining three isoforms from Gunn rats had normal UDPGT activity.

\section{Methods}

Material. Syngeneic Wistar rats (RHA strain) and Gunn rats congeneic with the Wistar (RHA) rats except for the jaundice locus were obtained from Dr. Carl Hansen (National Institutes of Health, Bethesda, MD). Wistar (RHA) rats were maintained in syngeneic state in the Carlson Animal Institute, University of Chicago, by inbreeding for $\mathbf{4 0}$ generations 
and backcrossing every fifth generation. Gunn rats were maintained in congeneic state by breeding homozygous males with obligate heterozygous females, produced by breeding between male Gunn rats and female Wistar (RHA) rats. Male animals of both strains (250-300 g) were maintained on a 12-h light/dark cycle and fed standard rat chow ad lib., until decapitation under light ether anesthesia.

Chromatofocusing gel (Polybuffer Exchanger 94), chromatofocusing buffer (Polybuffer 96), and phenyl-Sepharose 4B were obtained from Pharmacia, Inc., Uppsala, Sweden. UDP-hexanolamine was synthesized and linked to cyanogen bromide-activated Sepharose 4B according to Tukey and Tephly (34). All other reagents were of the purest available grade; their sources have been previously reported $(12,13)$.

Separation and purification of UDPGT isoforms. Microsomal fractions from Wistar and Gunn rat livers were prepared. Proteins were solubilized and UDPGT isoforms were resolved by chromatofocusing (pH 9.4 to 6.0) as previously described (13). UDP-glucuronosyltransferase activities toward 4-nitrophenol, testosterone, androsterone, and bilirubin were assayed in the chromatofocusing fraction in the presence of phosphatidylcholine liposomes as previously described (10-13). Protein was quantitated according to Bradford with bovine serum albumin (BSA) as standard (35).

Enzyme-linked immunosorbent assay. The concentration of UDPGT was determined in chromatofocusing fractions using an enzyme-linked immunosorbent assay (ELISA) (36). 0.05-ml aliquots from chromatofocusing fractions were applied to ELISA plate wells and incubated for $16 \mathrm{~h}$ at $4^{\circ} \mathrm{C}$. Unsaturated protein binding sites were blocked with $1 \%$ BSA in phosphate buffered saline (PBS) (pH 7.4). After washing with PBS containing Tween 20 (33), anti-rat UDPGT rabbit serum, recognizing all UDPGT transferase isoforms (2), was added at 1:500 dilution in PBS containing 1\% BSA. Antibody binding was quantitated by incubation with alkaline phosphatase-conjugated anti-rabbit IgG, followed by assay of alkaline phosphatase activity using p-nitrophenol 1-phosphate as substrate. The reaction product was quantitated from absorbance at $420 \mathrm{~nm}$ with an automated ELISA plate reader. Known amounts of purified UDPGT isoforms I-V were used as standards for quantitation of UDPGT concentrations in each fraction.

Affinity chromatography. Chromatofocusing fractions I (elution $\mathrm{pH}$ 8.8), II (elution pH 8.6), III (elution pH 8.0), IV (elution pH 7.8), and $\mathrm{V}$ (elution $\mathrm{pH} 7.5$ ) were enzymatically active in Wistar rats. These fractions and the corresponding Gunn rat fractions (see Fig. 1) were made $5 \mathrm{mM}$ in $\mathrm{MgCl}_{2}$ and subjected to affinity chromatography on UDPhexanolamine-Sepharose 4B (13). For isoform I, the affinity column was washed sequentially with 3 bed volumes of $20 \mathrm{mM}$ ethanolamine/acetate, pH 8.0 , containing $0.5 \mathrm{mg} / \mathrm{ml}$ Emulgen 911 (termed buffer A) containing $30 \mathrm{mM} \mathrm{KCl}$, buffer A containing $40 \mu \mathrm{M}$ UDP-glucuronic acid, and buffer A containing $2 \mathrm{mM}$ UDP-glucuronic acid; the final wash contained pure isoform I. Affinity chromatography of other isoforms was performed as previously described (13).

Phenyl-Sepharose $4 B$ chromatography. To remove UDP-glucuronic acid and minor contaminating proteins, the affinity chromatographypurified UDPGT isoforms were subjected to phenyl-Sepharose $4 \mathrm{~B}$ chromatography as previously described (12). In brief, the fractions were made $0.2 \mathrm{M}$ in $\left(\mathrm{NH}_{4}\right)_{2} \mathrm{SO}_{4}$ and applied to a phenyl-Sepharose $4 \mathrm{~B}$ column equilibrated with $25 \mathrm{mM}$ Tris/ $\mathrm{HCl}$, pH 8.0, containing $0.5 \mathrm{mg} / \mathrm{ml} \mathrm{Emul-}$ gen 911 and $0.2 \mathrm{M}\left(\mathrm{NH}_{4}\right)_{2} \mathrm{SO}_{4}$. After washing the column with 4 bed volumes of $25 \mathrm{mM}$ Tris, $\mathrm{HCl}, \mathrm{pH} 8.0$, enzyme was eluted with 2 bed volumes of $25 \mathrm{mM}$ Tris/HCl, $\mathrm{pH} 8.0$, containing $5 \mathrm{mg} / \mathrm{ml}$ Emulgen 911 .

Enzyme assay. UDPGT activities for 4-nitrophenol (31), testosterone (13), androsterone (11) and 4'-OH-DAB (12) were assayed in solubilized microsomes and chromatographic fractions as previously described. For chromatographic fractions, phosphatidylcholine liposomes were added to the incubation mixture. The liposomes were freshly prepared from egg phosphatidylcholine as described (12). For assay of UDPGT activity with bilirubin as substrate, $1.0 \mathrm{mg} / \mathrm{ml}$ phosphatidylcholine was used; other incubation mixtures contained $0.1 \mathrm{mg} / \mathrm{ml}$ (13). To determine the effect of diethylnitrosamine (DEN), chromatofocusing fractions were assayed for UDPGT activity for various substrates in the presence or absence of $15 \mathrm{mM}$ DEN.
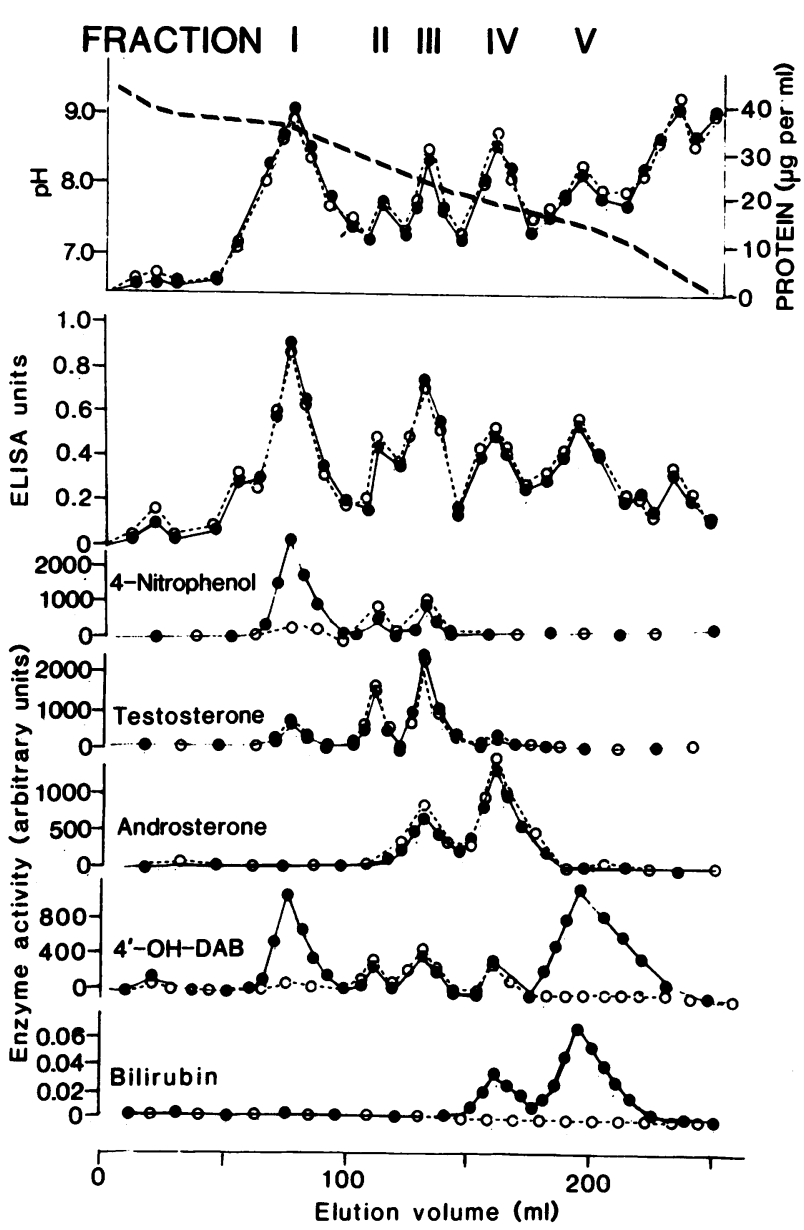

Figure 1. Chromatofocusing of solubilized microsomal fractions from Wistar and Gunn rat liver. Wistar (solid line) or Gunn rat (dashed line) liver microsomes were solubilized; proteins were separated by chromatofocusing. Immunoreactive UDPGT was determined by ELISA. Transferase activities toward various substrates were determined after reconstitution with phosphatidylcholine liposomes as described in the Methods. Data are from single representative experiments.

$\mathrm{NaDodSO}_{4} /$ polyacrylamide gel electrophoresis (PAGE). Solubilized hepatic microsomal fractions from Wistar (RHA) and Gunn rats, enzymatically active chromatofocusing fractions from Wistar (RHA) rats, corresponding fractions from Gunn rats, and purified UDPGT isoforms from Wistar and Gunn rats were subjected to electrophoresis on NaDodSO $_{4} / 10 \%$ polyacrylamide slab gels (37). Proteins were visualized by silver staining (38).

Immunotransblot. Enzymatically active chromatofocusing fractions from Wistar (RHA) rat and corresponding Gunn rat fractions (fractions I-V) were subjected to $\mathrm{NaDodSO}_{4} / \mathrm{PAGE}$. The proteins were electroblotted to nitrocellulose sheets. Immunotransblotting (39) was performed with the anti-rat UDPGT (rabbit) antiserum, which recognizes all UDPGT isoforms (2). Antibody binding was recognized with ${ }^{125}$ I-staphylococcal protein A and autoradiography.

\section{Results}

Separation of UDPGT activities toward various substrates. Fig. 1 shows UDPGT activity toward various substrates in solubilized hepatic microsomal fractions from Wistar (RHA) and congeneic Gunn rats. Protein recovery in fractions and UDPGT content are also shown. Protein recoveries and specific UDPGT activities 
in the chromatofocusing fractions are shown in Table I. Five chromatofocusing fractions (elution $\mathrm{pH} \mathrm{8.7,} \mathrm{8.4,} \mathrm{8.0,} \mathrm{7.8,} \mathrm{and}$ 7.5 , respectively) from Wistar rats had UDPGT activity toward various substrates after reconstitution with phosphatidylcholine liposomes (Fig. 1). Fraction I (elution pH 8.9) from Wistar rats was active toward 4-nitrophenol; the corresponding fraction from Gunn rats contained equivalent amounts of protein, but had only $10 \%$ of UDPGT activity (Table I). Fraction V (elution pH 7.5) from Wistar (RHA) rats was active toward bilirubin; the corresponding Gunn rat fractions had no UDPGT activity (Fig. 1, Table I) but contained approximately equal amounts of protein (Table I). The other chromatofocusing fractions from Wistar and Gunn rats contained equivalent amounts of protein and substrate-specific UDPGT activities except for fraction IV from Gunn rats, which had normal activity toward androsterone and 4'-OH-DAB, but was inactive with bilirubin as a substrate (Table I). It should be noted that the solubilized microsomal fractions contain endogenous membrane lipids and are fully active without the addition of liposomes, whereas UDPGT activity in the chromatofocusing or subsequent chromatographic fractions depend on reconstitution with added phosphatidylcholine liposomes. Because of this difference in the assay methods, the degree of purification cannot be quantitatively calculated from the enhancement of UDPGT-specific activity in the purified fractions.
Purification and $\mathrm{NaDodSO}_{4} / \mathrm{PAGE}$ of UDPGT isoforms. Table II shows protein recovery and UDPGT-specific activities of isoforms I-V, purified by affinity and phenyl-Sepharose chromatography from the five enzymically active chromatofocusing fractions from Wistar and Gunn rats. Proteins from chromatofocusing fraction I (elution $\mathrm{pH}$ 8.9) were subfractionated by affinity chromatography; the $2 \mathrm{mM}$ UDP-glucuronic acid eluate (termed isoform I) had the highest specific UDPGT activity toward 4-nitrophenol (13). Fig. 2 shows $\mathrm{NaDodSO}_{4} /$ polyacrylamide gel electrophorograms of purified UDPGT isoforms. Isoforms I $\left(M_{\mathrm{r}} 51,000\right)$, II $\left(M_{\mathrm{r}} 52,000\right)$, IV $\left(M_{\mathrm{r}} 53,000\right)$, and V $\left(M_{\mathrm{r}}\right.$ 53,000 ) from Wistar (RHA) and Gunn rat liver showed single silver-stained bands; isoform III revealed two bands $\left(M_{\mathrm{r}} 52,000\right.$ and 53,000). Staining with Coomassie blue (data not shown) showed similar results.

Effect of DEN. When assays were performed in $15 \mathrm{mM} \mathrm{DEN}$, specific UDPGT activity in isoform I from Gunn rat liver was increased 9-12-fold to the level seen in isoform I from Wistar rats (Table III). DEN did not activate Gunn rat isoform $\mathrm{V}$ or affect activities of isoforms II, III, and IV in normal or Gunn rats.

Immunotransblot. Each UDPGT isoform from Wistar and Gunn rats was recognized by anti-UDPGT (rabbit) antiserum (Fig. 3).

Table I. Protein Recovery and UDPGT Specific Activities in Chromatofocusing Fractions of Solubilized Hepatic Microsomal Fractions from Wistar (RHA) and Gunn Rats

\begin{tabular}{|c|c|c|c|c|c|c|}
\hline & & Fraction I & Fraction II & Fraction III & Fraction IV & Fraction V \\
\hline Elution pH & microsomes & 8.9 & 8.4 & 8.0 & 7.8 & 7.5 \\
\hline \multicolumn{7}{|c|}{ Protein recovery $(\mathrm{mg})$} \\
\hline Wistar rats & $82 \pm 5$ & $1.90 \pm 0.79$ & $0.23 \pm 0.03$ & $0.80 \pm 0.09$ & $0.76 \pm 0.05$ & $0.71 \pm 0.09$ \\
\hline Gunn rats & $86 \pm 6$ & $1.95 \pm 0.65$ & $0.21 \pm 0.07$ & $0.76 \pm 0.10$ & $0.78 \pm 0.09$ & $0.76 \pm 0.11$ \\
\hline Substrate & \multicolumn{6}{|c|}{ UDPGT activity (nmol per min per mg protein) } \\
\hline \multicolumn{7}{|l|}{ 4-Nitrophenol } \\
\hline Wistar rats & $153 \pm 19$ & $1968 \pm 208$ & $789 \pm 79$ & $898 \pm 108$ & $45 \pm 5$ & 0 \\
\hline Gunn rats & $69 \pm 7^{*}$ & $188 \pm 19^{*}$ & $798 \pm 80$ & $889 \pm 98$ & $39 \pm 5$ & 0 \\
\hline \multicolumn{7}{|c|}{ 4-Methylumbelliferone } \\
\hline Wistar rats & $16 \pm 2$ & $343 \pm 41$ & $11 \pm 3$ & $12 \pm 4$ & $98 \pm 9$ & 0 \\
\hline Gunn rats & $7 \pm 1^{*}$ & $38 \pm 31^{*}$ & $12 \pm 4$ & $13 \pm 5$ & $89 \pm 10$ & 0 \\
\hline \multicolumn{7}{|l|}{ Testosterone } \\
\hline Wistar rats & $5 \pm 0.7$ & $60 \pm 5$ & $184 \pm 12$ & $172 \pm 20$ & $24 \pm 3$ & 0 \\
\hline Gunn rats & $6 \pm 0.5$ & $58 \pm 5$ & $179 \pm 19$ & $180 \pm 17$ & $23 \pm 2$ & 0 \\
\hline \multicolumn{7}{|l|}{ Androsterone } \\
\hline Wistar rats & $8 \pm 1$ & 0 & 0 & $155 \pm 19$ & $225 \pm 20$ & 0 \\
\hline Gunn rats & $6 \pm 1$ & 0 & 0 & $160 \pm 23$ & $231 \pm 19$ & 0 \\
\hline \multicolumn{7}{|l|}{ 4'-OH-DAB } \\
\hline Wistar rats & $0.7 \pm 0.1$ & $8 \pm 0.7$ & $5 \pm 0.4$ & $4 \pm 0.5$ & $5 \pm 0.4$ & $11 \pm 0.7$ \\
\hline Gunn rats & $0.2 \pm 0.03^{*}$ & $0.1 \pm 0.01^{*}$ & $5 \pm 0.6$ & $4 \pm 0.4$ & $6 \pm 0.8$ & $0^{*}$ \\
\hline \multicolumn{7}{|l|}{ Bilirubin } \\
\hline Wistar rats & $0.2 \pm 0.06$ & 0 & 0 & 0 & $5.1 \pm 0.9$ & $9.5 \pm 1.0$ \\
\hline Gunn rats & $0^{*}$ & 0 & 0 & 0 & $0^{*}$ & $0^{*}$ \\
\hline
\end{tabular}

Rat liver microsomes were solubilized and proteins were separated by chromatofocusing (range from pH 9.5 to 6.0). Enzyme activities were determined after reconstitution with phosphatidylcholine liposomes as described in the Methods section. Data represent means \pm SEM for six experiments. $\left(^{*}\right)$ Indicates that the value obtained from Gunn rats differs significantly from that obtained from Wistar rats $(P<0.01)$. 
Table II. Protein Recovery and UDPGT Specific Activity in Purified Transferase Isoforms from Wistar (RHA) and Gunn Rats

\begin{tabular}{|c|c|c|c|c|c|}
\hline Transferase isoforms & I & II & III & IV & $\mathbf{v}$ \\
\hline \multicolumn{6}{|c|}{ Protein recovery $(\mu \mathrm{g})$} \\
\hline Wistar rats & $236 \pm 20$ & $100 \pm 13$ & $298 \pm 38$ & $201 \pm 25$ & $171 \pm 25$ \\
\hline Gunn rats & $243 \pm 25$ & $98 \pm 10$ & $308 \pm 35$ & $192 \pm 22$ & $180 \pm 19$ \\
\hline Substrate & \multicolumn{5}{|c|}{ Enzyme specific activity (nmol/min per mg protein) } \\
\hline \multicolumn{6}{|l|}{ 4-Nitrophenol } \\
\hline Wistar rats & $4580 \pm 441$ & $1490 \pm 151$ & $1540 \pm 189$ & $58 \pm 6$ & 0 \\
\hline Gunn rats & $470 \pm 51^{*}$ & $1500 \pm 160$ & $1550 \pm 170$ & $61 \pm 7$ & 0 \\
\hline \multicolumn{6}{|c|}{ 4-Methylumbelliferone } \\
\hline Wistar rats & $1210 \pm 140$ & $60 \pm 7$ & $82 \pm 10$ & $180 \pm 16$ & 0 \\
\hline Gunn rats & $131 \pm 12^{*}$ & $73 \pm 6$ & $80 \pm 12$ & $191 \pm 20$ & 0 \\
\hline \multicolumn{6}{|l|}{ Testosterone } \\
\hline Wistar rats & 0 & $330 \pm 28$ & $300 \pm 24$ & $20 \pm 7$ & 0 \\
\hline Gunn rats & 0 & $325 \pm 30$ & $305 \pm 35$ & $15 \pm 7$ & 0 \\
\hline \multicolumn{6}{|l|}{ Androsterone } \\
\hline Wistar rats & 0 & 0 & $89 \pm 10$ & $310 \pm 41$ & 0 \\
\hline Gunn rats & 0 & 0 & $90 \pm 9$ & $330 \pm 43$ & 0 \\
\hline \multicolumn{6}{|l|}{ 4'-OH-DAB } \\
\hline Wistar rats & $19 \pm 3$ & $9 \pm 1$ & $6 \pm 0.8$ & $13 \pm 2$ & $29 \pm 3$ \\
\hline Gunn rats & $1 \pm 0.2^{*}$ & $10 \pm 2$ & $6 \pm 0.6$ & $12 \pm 3$ & $0^{*}$ \\
\hline \multicolumn{6}{|l|}{ Bilirubin } \\
\hline Wistar rats & 0 & 0 & 0 & $15 \pm 3$ & $28 \pm 6$ \\
\hline Gunn rats & 0 & 0 & 0 & $0^{*}$ & $0^{*}$ \\
\hline
\end{tabular}

UDPGT isoforms were purified as described in the Methods section. Data are means \pm SEM for six experiments. $\left(^{*}\right)$ Indicates significant difference from the value obtained from Wistar rats $(P<0.01)$.

\section{Discussion}

The chromatographic methods were based on our recent study of normal rat liver UDPGT $(12,13)$, which indicated that there are at least four, and possibly seven, distinct UDPGT isoforms. Chromatofocusing of solubilized liver microsomes results in a high degree of purification of UDPGT; only 4-5\% of total applied protein is eluted by chromatofocusing in the $\mathrm{pH}$ range of 9.4 to 7.5. As a result, protein concentrations in the chromatofocusing fractions roughly parallel immunoreactive UDPGT concentrations as determined by ELISA and UDPGT activities toward various substrates. Because of the high degree of purification in the chromatofocusing step, further purification of fractions II$V$ resulted in only minor enhancement of specific UDPGT activities. Specific UDPGT activity of purified isoform III toward androsterone (Table I) was lower than that in chromatofocusing fraction III (Table II). This is consistent with our findings in previous studies (13) and may represent removal of contaminating UDPGT isoform IV during affinity chromatography. Proteins in chromatofocusing fraction I were resolved into three fractions by affinity chromatography; the 2 mM UDP-glucuronic acid fraction (isoform I) had the highest specific activity for 4nitrophenol. Isoform I in this report corresponds to Isoform Ic of a previously reported study (13).

Gunn rats were originally described as jaundiced mutants of the Wistar strain (17). Although the lack of UDPGT activity toward bilirubin is a common characteristic of all Gunn rats
(18), colonies of Gunn rats maintained in various laboratories show considerable heterogeneity regarding UDPGT activity toward 4-nitrophenol (21-24). Wistar rats are also heterogeneous with regard to UDPGT activity toward other substrates, such as androsterone (32). Because of variabilities in Wistar and Gunn strains, quantitative comparison of UDPGT activities toward substrates other than bilirubin between outbred Gunn and Wistar rats is unreliable. Recent development of inbred Wistar (RHA) rats and congeneic Gunn rats, which have the same genetic pool except for the jaundice locus, permitted precise comparison of substrate-specific UDPGT activities between the two (33).

One functionally defective form of UDPGT was previously isolated from Gunn rat liver by Weatherill and Burchell (29). This form was enzymically inactive toward bilirubin but was activated toward 4-nitrophenol in the presence of DEN. However, in a later study from the same laboratory, both phenolUDPGT and bilirubin-UDPGT were reported to be undetectable by immunotransblot studies (31). Using the high resolution power of chromatofocusing $(10,12,13)$, we isolated two distinct functionally defective UDPGT isoforms in addition to three isoforms with normal enzymic activity. Both defective isoforms were recognized by the anti-rat UDPGT (rabbit) antiserum. The differences probably result from use of inbred Wistar rats and Gunn rats congeneic with the Wistar rats. This use minimizes the variation of UDPGT within the Wistar strain. Gunn rat UDPGT isoform I has a lower specific enzyme activity compared to that in congeneic controls. This functionally defective isoform 


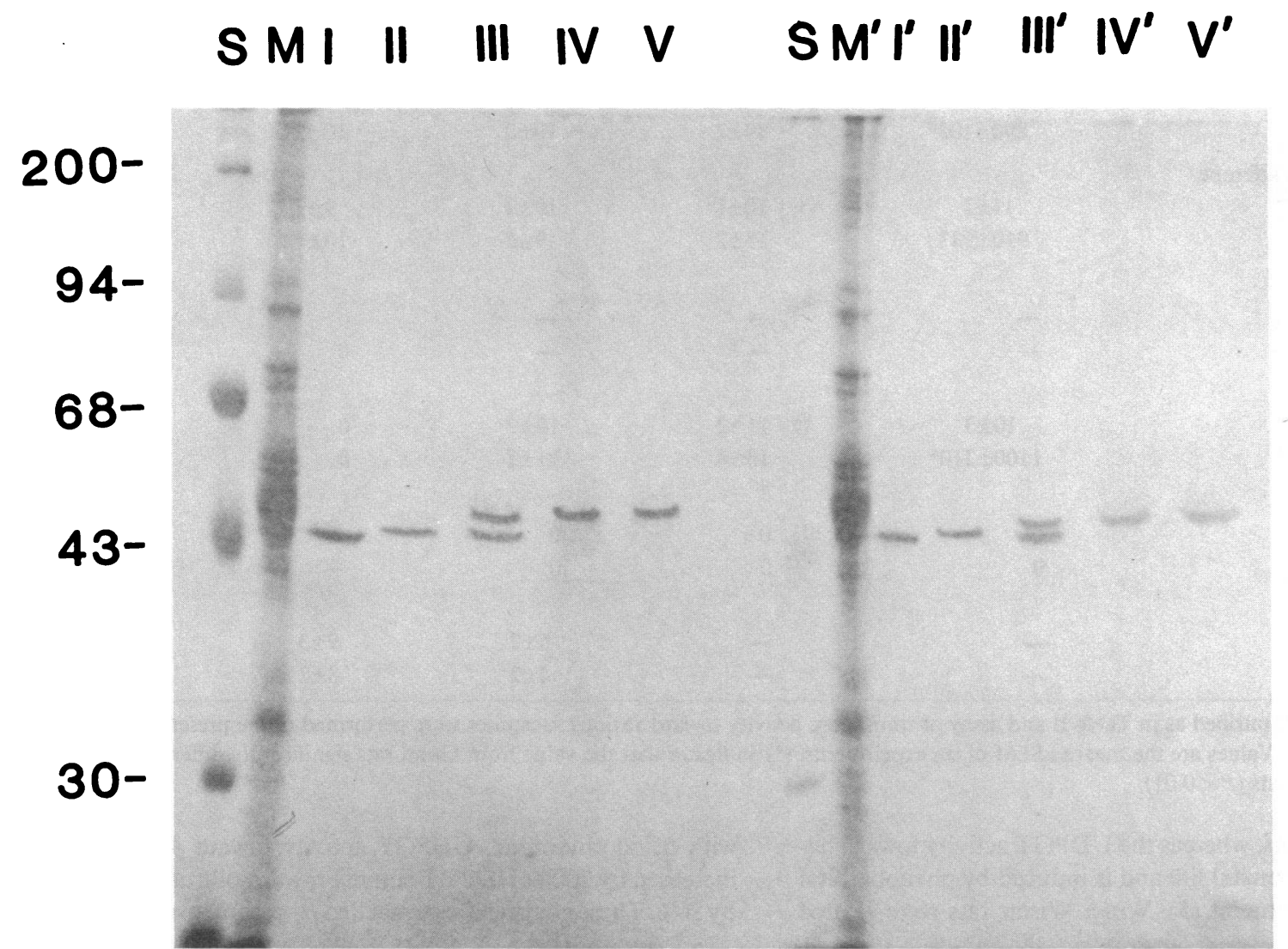

Figure 2. $\mathrm{NaDodSO}_{4} / \mathrm{PAGE}$ of Wistar and Gunn rat UDPGT isoforms. Chromatofocusing was performed as in Fig. 1. Proteins in $\mathrm{pH}$ 8.9 fractions were further fractionated by UDP-hexanolamine-sepharose 4B chromatography. Isoforms I (from Wistar rat) and I' (from Gunn rat) were purified from $30 \mathrm{mM}$ UDP-glucuronic acid eluate by phenyl-sepharose 4B chromatography. Other isoforms were purified from Wistar (II-V) and Gunn rat $\left(\mathrm{II}^{\prime}-\mathrm{V}^{\prime}\right)$ liver microsomal fractions as described in Methods. $M_{\mathrm{r}}$ standards $(\mathrm{S})$, solubilized Wistar $(\mathrm{M})$ or Gunn rat $\left(\mathbf{M}^{\prime}\right)$ liver microsomal proteins and purified isoforms were electrophoresed on $\mathrm{NaDodSO}_{4} / 10 \%$ polyacrylamide slab gels. Proteins were visualized by silver staining. exhibits normal chromatofocusing elution $\mathrm{pH}$ and $M_{\mathrm{r}}$ value on $\mathrm{NaDodSO}_{4} / \mathrm{PAGE}$. UDPGT activity of Gunn rat isoform I toward 4-nitrophenol and 1-naphthol was restored to normal upon addition of DEN. The increase in transferase activity toward 4nitrophenol was limited to isoform I; 4-nitrophenol-UDPGT activity of isoforms II and III, mainly active toward testosterone, did not increase upon addition of DEN. Transferase isoforms II, III, and IV from Gunn rats had normal chromatofocusing elution pH, electrophoretic mobility, and UDPGT-specific activities toward their respective steroid substrates. These results are consistent with previously reported normal UDPGT activity toward steroid substrates in Gunn rats (27). However UDPGT isoform IV from Gunn rats did not have any activity toward bilirubin. Normal UDPGT isoform $V$ also catalyzes the transfer of glucose or xylose moieties to bilirubin from UDP-glucose and UDP-xylose, respectively (12). Neither isoform IV nor isoform $V$ from Gunn rats catalyzed these reactions (data not shown). A possible explanation for the absence of UDPGT activity in Gunn rat isoform IV toward bilirubin and normal activity for androsterone is that the "purified" isoform IV may contain two forms of UDPGT that are not distinguishable by charge or mobility on $\mathrm{NaDodSO}_{4} / \mathrm{PAGE}$. Gunn rat UDPGT isoform $\mathrm{V}$, which had the same chromatofocusing elution $\mathrm{pH}$ and electrophoretic mobility as did normal isoform $\mathrm{V}$, had no
UDPGT activity with or without added DEN; this isoform was recognized as UDPGT by ELISA and immunotransblot (2).

Although UDPGT isoforms are quite specific for endogenous substrates, they are less specific for xenobiotics. For example, $4^{\prime}-\mathrm{OH}-\mathrm{DAB}$ is a substrate for all five UDPGT isoforms. 4'-OHDAB behaves like 4-nitrophenol with isoform I regarding decreased rate of glucuronidation in Gunn rats and normalization of UDPGT activity in the presence of DEN. However, with isoform V, 4'-OH-DAB behaves like bilirubin as there is no UDPGT activity and addition of DEN has no effect. Thus, the glucuronidation of various aglycone substrates of UDPGT isoform I are similarly affected by the inherited defect in Gunn rats. Similarly, Gunn rat UDPGT isoform V was inactive toward both bilirubin and 4'-OH-DAB.

Alterations in membrane lipids could conceivably affect UDPGT activities (40). However, in this study, the functional defect persisted after isoform purification and reconstitution in defined phospholipid liposomes, thus indicating that a defect exists in UDPGT rather than in its membrane environment.

Several lines of evidence indicate that substrate-specific UDPGT activities toward 4-nitrophenol and bilirubin, defective in Gunn rats, may be catalyzed by two distinct UDPGT isoforms. UDPGT activity toward 4-nitrophenol appears in late fetal life in rats and is induced by treatment with 3-methylcholanthrene 


\begin{tabular}{|c|c|c|c|c|c|}
\hline \multirow[b]{2}{*}{ Substrate } & \multicolumn{5}{|c|}{ Percent increase of transferase-specific activity in the presence of $15^{\circ} \mathrm{mM}$ DEN } \\
\hline & Isoforms I & II & III & IV & $\mathbf{V}$ \\
\hline \multicolumn{6}{|l|}{ 4-Nitrophenol } \\
\hline Wistar rats & $10 \pm 2$ & $10 \pm 2$ & $9 \pm 1$ & $9 \pm 1$ & 一 \\
\hline Gunn rats & $890 \pm 102^{*}$ & $14 \pm 2$ & $10 \pm 2$ & $10 \pm 2$ & - \\
\hline \multicolumn{6}{|c|}{ 4-Methylumbelliferone } \\
\hline Wistar rats & $11 \pm 2$ & $10 \pm 1$ & $10 \pm 2$ & $9 \pm 2$ & - \\
\hline Gunn rats & $910 \pm 98^{*}$ & $13 \pm 2$ & $9 \pm 2$ & $10 \pm 1$ & 一 \\
\hline \multicolumn{6}{|l|}{ Bilirubin } \\
\hline Wistar rats & - & - & - & 0 & 0 \\
\hline Gunn rats & - & - & - & 0 & 0 \\
\hline \multicolumn{6}{|l|}{$4^{\prime} \mathrm{OH}-\mathrm{DAB}$} \\
\hline Wistar rats & $10 \pm 3$ & $11 \pm 2$ & $10 \pm 2$ & 0 & 0 \\
\hline Gunn rats & $1100 \pm 210^{*}$ & $15 \pm 4$ & $11 \pm 2$ & 0 & 0 \\
\hline \multicolumn{6}{|l|}{ Testosterone } \\
\hline Wistar rats & 0 & 0 & 0 & - & - \\
\hline Gunn rats & 0 & 0 & 0 & - & - \\
\hline \multicolumn{6}{|l|}{ Androsterone } \\
\hline Wistar rats & - & - & $5 \pm 2$ & $9 \pm 3$ & - \\
\hline Gunn rats & - & - & $4 \pm 2$ & $8 \pm 2$ & - \\
\hline
\end{tabular}

UDPGT isoforms were purified as in Table II and assay or transferase activity toward various substrates were performed in the presence or absence of $15 \mathrm{mM}$ DEN. Values are the means \pm SEM of six expeirments. $\left(^{*}\right)$ Indicates that the value from Gunn rats significantly differs from that obtained from Wistar rats $(P<0.01)$.

and other carcinogens, whereas the UDPGT activity toward bilirubin appears in neonatal life and is induced by phenobarbital (4) or clofibrate treatment (5). When Wistar rats were treated with triiodothyronine, UDPGT activity toward 4-nitrophenol increased by $200 \%$; UDPGT activity toward bilirubin decreased by $80 \%$. These changes are parallelled by commensurate changes

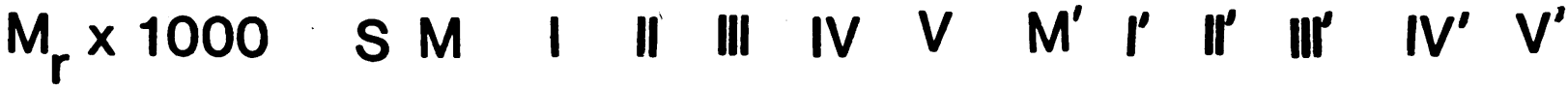

\section{0-}

97.4-

68-

43-

25.7-

18.4-

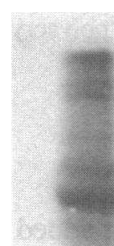


in the abundance of the corresponding UDPGT isoforms (7). Isoform I and V, which catalyze the glucuronidation of 4-nitrophenol and bilirubin, respectively, were completely separated by chromatofocusing in this study. We previously demonstrated that isoforms I and V differ in tryptic peptide maps indicating difference in their protein structure (13).

Nonhemolytic unconjugated hyperbilirubinemia in Gunn rats is inherited as a Mendelian recessive characteristic (17) that may be associated with a defect in a single structural or regulatory locus. Although the present study does not address the question of the mechanism of the functional defect of UDPGTs isoforms in Gunn rats, the results indicate that immunoreactive UDPGT isoforms $\mathrm{I}$ and $\mathrm{V}$ are present in approximately normal amounts in Gunn rat liver. Therefore, the functional deficit appears to result from specific functionally defective UDPGT isoforms. This is consistent with the conclusion reached by Nakata et al. (24) on the basis of kinetic studies using normal and Gunn rat liver microsomes. A functional defect in two distinct UDPGT isoforms in Gunn rats suggests that isoforms I and V may be products of a single defective gene and are distinguished by posttranscriptional or posttranslational modification. An alternative explanation for the functional defect of multiple UDPGT isoforms in Gunn rats proposed by Zakim and coworkers $(24,30)$ is that UDPGT may be oligomers and the defective isoforms may share a common defective subunit. Results of radiation inactivation studies support the concept of oligomeric structure of UDPGT isoforms (41). Interaction of a single defective subunit with various other subunits may modify the properties of the UDP-glucuronic acid-binding site (24) or the aglycone-binding site, leading to variability in the degree of defective glucuronidation of different aglycones in the Gunn rat.

\section{Acknowledgments}

The authors thank M. Lederstein and R. Stram for technical assistance. This work was supported in part by National Institutes of Health grants AM-34357, AM-2019, and AM-17702. Dr. J. Roy Chowdhury is the recipient of a Research Career Award (AM-1016) of the National Institutes of Health.

\section{References}

1. Kasper, C. B., and D. Henton. 1980. Glucuronidation. In Enzymatic Basis of Detoxication. W. B. Jakoby, editor. Academic Press, New York. 4-36.

2. Roy Chowdhury, J., P. M. Novikoff, N. Roy Chowdhury, and A. B. Novikoff. 1985. Distribution of UDPglucuronosyltransferase in rat tissue. Proc. Natl. Acad. Sci. USA. 82:2990-2994.

3. Dutton, G. J. 1980. Glucuronidation of Drugs and Other Compounds. CRC Press, Boca Raton, Florida. 13-16.

4. Wishart, G. J. 1978. Functional heterogeneity of UDP-glucuronyltransferase as indicated by its differential development and inducibility by glucocorticoids. Biochem. J. 174:485-489.

5. Bock, K. W., D. Jostling, W. Lillienblum, and H. Pfeil. 1979. Purification of rat liver UDP-glucuronyltransferase: separation of two enzyme forms inducible by 3-methylcholanthrene or phenobarbital. Eur. J. Biochem. 98:315-317.

6. Lillienblum, W., A. K. Walli, and K. W. Bock. 1982. Differential induction of rat liver microsomal UDP-glucuronosyltransferase activities by various inducing agents. Biochem. Pharmacol. 31:907-913.

7. Roy Chowdhury, J., N. Roy Chowdhury, A. D. Moscioni, R. Tukey, T. R. Tephly, and I. M. Arias. 1983. Differential regulation by triiodothyronine of substrate-specific uridinediphosphoglucuronate glucuronosyltransferases in rat liver. Biochim. Biophys. Acta. 761:58-65.

8. Weatherill, P. J., and B. Burchell. 1980. The separation and pu- rification of rat liver UDP-glucuronosyltransferase activities towards testosterone and estrone. Biochem. J. 189:377-380.

9. Burchell, B. 1981. Identification and purification of multiple forms of UDP-glucuronosyltransferase. Rev. Biochem. Toxicol. 3:1-32.

10. Falany, C. N., J. Roy Chowdhury, N. Roy Chowdhury, and T. R. Tephly. 1983. Steroid 3- and 17-OH-UDPglucuronosyltransferase activities in rat and rabbit liver microsomes. Drug Metab. Dispos. 11: $426-432$.

11. Falany, C. N., and T. R. Tephly. 1983. Separation, purification and characterization of three isozymes of UDP-glucuronyltransferase from rat liver microsomes. Arch. Biochem. Biophys. 227:248-258.

12. Roy Chowdhury, N., I. M. Arias, M. Lederstein, and J. Roy Chowdhury. 1986. Substrates and products of purified rat liver bilirubin UDP-glucuronosyltransferase. Hepatology (Baltimore). 6:123-128.

13. Roy Chowdhury, J., N. Roy Chowdhury, C. N. Falany, T. R. Tephly, and I. M. Arias. 1986. Isolation and characterization of multiple forms of rat liver UDP-glucuronate glucuronosyltransferase. Biochem. J. 233:827-837.

14. Blanckaert, N., J. Fevery, K. P. M. Heirwegh, and F. Compernolle. 1977. Characterization of the major diazo-positive pigments in bile of homozygous Gunn rats. Biochem. J. 164:237-243.

15. Wolkoff, A. W., J. Roy Chowdhury, and I. M. Arias. 1983. Hereditary jaundice and disorders of bilirubin metabolism. In Metabolic Basis of Inherited Diseases. J. B. Stanbury, J. B. Wyngaarden, D. S. Fredrickson, J. L. Goldstein, and M. S. Brown, editors. McGraw-Hill Book Company, New York. Fifth ed. 1385-1420.

16. Roy Chowdhury, N., and J. Roy Chowdhury. 1983. Conjugation and excretion of bilirubin. Semin. Liver Dis. 3:11-23.

17. Gunn, C. H. 1938. Hereditary acholuric jaundice in a new mutant strain of rats. J. Hered. 29:137-142.

18. Schmidt, R., J. Axelrod, L. Hammaker, and R. L. Swarm. 1958. Congenital jaundice in rats due to a defect in glucuronide formation. $J$. Clin. Invest. 37:1123-1128.

19. Wolkoff, A. W., J. Roy Chowdhury, L. A. Gartner, A. L. Rose, L. Biempica, D. R. Giblin, D. Fink, and I. M. Arias. 1979. Crigler-Najjar syndrome, Type I in an adult male. Gastroenterology. 76:840-848.

20. Roy Chowdhury, J., A. W. Wolkoff, and I. M. Arias. 1982. Heme and bile pigment metabolism. In Liver: Biology and Pathobiology. I. M. Arias, D. Shafritz, D. Schacter, and H. Popper, editors. Raven Press, New York. 309-332.

21. Stevenson, I. H., D. T. Greenwood, and J. McEwen. 1968. Hepatic UDP-glucuronosyltransferase in Wistar and Gunn rats: in vitro activation by diethylnitrosamine. Biochem. Biophys. Res. Commun. 32:866-872.

22. Drucker, W. D. 1968. Glucuronic acid conjugation of tetrahydrocortisone and p-nitrophenol in the homozygous Gunn rat. Proc. Soc. Exp. Biol. Med. 129:308-312.

23. Pukka, R., P. Tanner, and O. Hanninen. 1973. Enzymes of the glucuronic acid pathway in Wistar and Gunn rats in their heterozygotes. Biochem. Genet. 9:343-355.

24. Nakata, D., D. Zakim, and D. Vessey. 1975. Defective function of a microsomal UDP-glucuronyltransferase in Gunn rats. Proc. Natl. Acad. Sci. USA. 73:289-292.

25. Arias, I. M. 1961. Ethereal and N-linked glucuronide formation by normal and Gunn rats in vitro and in vivo. Biochem. Biophys. Res. Commun. 6:81-85.

26. Flock, E. V., J. L. Bollman, C. A. Owen, and P. E. Zollman. 1965. Conjugation of thyroid hormones and analogs by the Gunn rat. Endocrinology. 77:303-310.

27. Javitt, N. B. 1966. Ethereal and acyl glucuronide formation in the homozygous Gunn rat. Am. J. Physiol. 211:424-430.

28. Mowat, A. P., and I. M. Arias. 1970. Observation of the effect of diethylnitrosamine on glucuronide formation. Biochim. Biophys. Acta. 212:175-180.

29. Weatherill, P. J., and B. Burchell. 1978. Reactivation of a pure defective UDP-glucuronosyltransferase from homozygous Gunn rat liver. FEBS (Fed. Eur. Biochem. Soc.) Lett. 87:207-211.

30. Zakim, D. 1974. Biochemical foundations of preventive medicine: the study of abnormal enzymes. Horiz. Biochem. Biophys. 1:97-134.

31. Scragg, I., C. Celier, and B. Burchell. 1985. Congenital jaundice 
in rats due to the absence of hepatic bilirubin UDP-glucuronyltransferase enzyme protein. FEBS (Fed. Eur. Biochem. Soc.) Lett. 183:37-42.

32. Matsui, M., and H. K. Watanabe. 1982. Classification and genetic expression of Wistar rats with high and low hepatic microsomal UDPglucuronosyltransferase activity toward androsterone. Biochem. J. 202: 171-178.

33. Mackenzie, P. I., and I. S. Owens. 1983. Differences in UDPglucuronosyltransferase activities in congeneic inbred rats homozygous and heterozygous for the jaundice locus. Biochem. Pharmacol. 32:37773781.

34. Tukey, R. H., R. E. Billings, and T. R. Tephly. 1978. Separation of estron estrone-UDP-glucuronyltransferase and p-nitrophenol-UDPglucuronyltransferase activities. Biochem. J. 171:659-663.

35. Bradford, M. 1976. A rapid and sensitive method for the quantitation of microgram quantities of protein utilizing the principle of protein dye binding. Anal. Biochem. 72:248-253.

36. Waller, A., D. Bidwell, and A. Bartlett. 1980. Enzyme-linked immunosorbent assay. In Manual of Clinical Immunology. N. R. Rose, and H. Friedman, editors. American Society of Microbiology, Washington, D.C. Second ed. 359-371.

37. Laemmli, U. K. 1970. Cleavage of structural proteins during the assembly of the head of bacteriophage T4. Nature (Lond.). 227:680-685.

38. Oakley, B. R., D. R. Kirsch, and R. Morris. 1980. A simplified ultrasensitive silver stain for detecting proteins in polyacrylamide gels. Anal. Biochem. 105:361-363.

39. Burnette, W. N. 1981. "Western blotting": electrophoretic transfer of proteins from sodium dodecyl sulfate-polyacrylamide gels to unmodified nitrocellulose and radiographic detection with antibody and radioiodinated protein A. Anal. Biochem. 112:195-203.

40. Jansen, P. L. M., and I. M. Arias. 1975. Delipidation and reactivation of UDP-glucuronosyltransferase from rat liver. Biochim. Biophys. Acta. 391:28-38.

41. Peters, W. H. M., P. L. M. Jansen, and H. Nauta. 1983. The molecular weights of UDP-glucuronosyltransferase determined with radiation inactivation analysis. J. Biol. Chem. 259:11701-11705. 